\title{
A influência do aporte de sedimentos fluviais na qualidade das águas superficiais da bacia do córrego Bom Jardim, Brasilândia/MS.
}

\author{
André Luiz Pinto ${ }^{1}$ \\ Gustavo Henrique de Oliveira ${ }^{2}$ \\ Gabrielle Alberta Pereira ${ }^{3}$ \\ ${ }^{1}$ Professor Dr. Associado II da UFMS/CPTL - Departamento de Ciências Humanas \\ Caixa Postal 210 - 79620-080 - Três Lagoas - MS, Brasil \\ andreluiz@cplt.ufms.br \\ ${ }^{2}$ Discente do Curso de Geografia Bacharelado da UFMS/CPTL - Bolsista de Iniciação Científica - \\ $\mathrm{CNPq}-\mathrm{PIBIC}$ \\ Rua Francisco Peres Marques, 320 - 16202-030 - Birigui - SP, Brasil \\ henriqueguo@hotmail.com \\ ${ }^{3}$ Discente do Curso de Geografia Bacharelado da UFMS/CPTL \\ Viela Particular, 2.423 - 79600-000 - Três Lagoas - MS, Brasil \\ gabialberta@gmail.com
}

\begin{abstract}
The improper use of the hídricos resources and the basin of the Good Stream Garden that passes in the unit of Cisalpina/CESP conservation for being carreando tons of sediments in the River Parana and causing frequent floods in the city of Brasilândia, therefore the necessity to evaluate the main uses and to monitor the qualities of superficial waters influences and it of the sediments on the basin, using as main pointer the dissolved oxygen that is of basic importance in the maintenance of the quality of the water. For this it analyzes are necessary to the water collections of the points to be analyzed, that they will receive the name from stations. In function of this desolating picture and the lack of scientific information technician/that it assists in the taking of mitigadoras and corrective measures, the present research is born, thus intending to subsidize the Basin of the Bom Jardim Garden.
\end{abstract}

Palavras-Chave: Qualidade da Água; Competência de Trasnporte Fluvial.

\section{Introdução}

A água constitui, atualmente, no fator limitante para o desenvolvimento agrícola, urbano e industrial, tendo em vista que a disponibilidade per capita de água doce vem sendo reduzida rapidamente, face ao aumento gradativo da demanda para seus múltiplos usos, em especial agricola e à contínua poluição dos mananciais ainda disponíveis.

A escassez de água não pode mais ser considerada como atributo exclusivo de regiões áridas e semi-áridas. Muitas áreas com recursos hídricos abundantes, mas insuficientes para atender a demandas excessivamente elevadas, também experimentam conflitos de usos e sofrem restrições de consumo que afetam o desenvolvimento econômico e a qualidade de vida (TUNDISI, 2003).

Para restabelecer o equilíbrio entre oferta e demanda de água e garantir a sustentabilidade do desenvolvimento econômico e social, é necessário que métodos e sistemas alternativos modernos sejam convenientemente desenvolvidos e aplicados em função de características de sistemas e centros de produção específicos. Nesse sentido, reuso, reciclagem, gestão da demanda, redução de perdas e minimização da geração de efluentes se constituem, em associação às práticas conservacionistas, nas palavras-chave mais importantes em termos de gestão de recursos hídricos e de redução da poluição. 
Anais II Seminário de Recursos Hídricos da Bacia Hidrográfica do Paraíba do Sul: Recuperação de Áreas Degradadas, Serviços Ambientais e Sustentabilidade, Taubaté, Brasil, 09-11 dezembro 2009, IPABHi, p. 189-198.

(doi:10.4136/serhidro.25)

A Lei $\mathrm{N}^{\circ} 9.433$ de 8 de janeiro de 1997 vem contemplar a importância da bacia hidrográfica, em seu principio primeiro: a adoção da bacia hidrográfica como unidade de planejamento, tendo como limites da bacia o perímetro da área a ser planejada.

A escolha da bacia hidrográfica como unidade de estudo, planejamento e gerenciamento da paisagem foi à base para diversos trabalhos que utilizaram diferentes abordagens metodológicas (BORMANN e LIKENS, 1967; O' SULLIVAN, 1979; ODUM, 1985; POLLETE, 1993; LIMA, 1994; PIRES, 1994; PIRES e SANTOS, 1995).

Para Rocha et.al (2000) qualquer tipo de uso do solo na bacia hidrográfica interfere no ciclo hidrológico, não importando o grau com que esse tipo de uso utiliza ou dependa diretamente da água. Pode ser verificado, por exemplo, que, embora a agricultura sem irrigação não retire água de um manancial superficial, sua presença interfere de forma indireta na erosão, com o aumento do escoamento superficial e conseqüentemente assoreamento dos corpos d'água, na redução da taxa de infiltração de água no solo, na diminuição do lençol freático, na alteração do padrão da vazão dos córregos etc. desde que o uso do recurso solo interfira no recurso água (PIRES e SANTOS, 1995).

Contudo tanto o uso e ocupação e manejo do solo das bacias influência na dinâmica do escoamento superficial, propiciando graus diferenciados de resistência às ações dos agentes externos e processo que modelam a sua morfologia, e consecutivamente os transportes de materiais que inter vem na qualidade da água desse manancial.

A bacia do Córrego Bom Jardim foi selecionada devido a suas nascentes ocorrerem na aldeia indígena Ofayé, cortar a cidade de Brasilândia, em médio curso e sua foz localizar-se na unidade de conservação RPPN Cisalpina, pertencente a CESP (Companhia Energética do Estado de São Paulo) e por estar carreando toneladas de sedimentos no Rio Paraná, no lago da represa de Porto Primavera.

O presente estudo justifica-se então, pela necessidade de embasar as decisões acerca do plano de recuperação, ordenamento e manejo da bacia, referente à origem e volume de sedimentos transportados ao longo da bacia, suas implicâncias diretas no contexto urbano de Brasilândia e seu entorno imediato, assim como na unidade de conservação Cisalpina da CESP e na aldeia Ofayé.

Para sua operacionalização selecionou-se oito estações nas quais foram monitorado o volume de sedimentos transportados pelo córrego Bom Jardim, no inverno de 2008 e verão de 2009

\section{MATERIAIS E MÉTODOS}

Para a mensuração dos parâmetros para a aferição da qualidade das águas superficiais do Córrego Bom Jardim, foram utilizados os equipamentos e métodos a baixo relacionados, no Quadro 01 .

Quadro 01: Parâmetros, Equipamentos e Métodos Utilizados para Análise da Qualidade das Águas Superficiais do Córrego Bom Jardim, no Município de Brasilândia/MS

\begin{tabular}{|l|l|l|}
\hline Parâmetros & Equipamentos & Método \\
\hline Oxigênio Dissolvido OD & Lutron DO - 5510 & Espectrofotométrico \\
\hline Condutividade & Tecnopon MCA - 150 & Eletrométrico \\
\hline Turbidez & Tecnopon TB 1000 & Eletrométrico \\
\hline pH & Phtek $\mathrm{pH}-100$ & Eletrométrico \\
\hline Temperatura & Lutron DO -5510 & Eletrométrico \\
\hline
\end{tabular}

O oxigênio dissolvido é um gás solúvel em água, com concentrações recomendáveis pelo CONAMA Resolução 357 de 17/03/05, classe 1, de 10,0 a $6,0 \mathrm{mg} / 1 \mathrm{O}_{2}$ em qualquer amostra, Tabela 01 e Quadro 02. O método espectrofotométrico utilizado pelo equipamento Lutron DO 
5510, será seguido para a verificação do oxigênio dissolvido. Segundo Araújo et al. (2004) o oxigênio dissolvido pode ser utilizado como indicador de qualidade das águas superficiais, pois a proliferação bacteriológica depende diretamente de suas concentrações, constituindo de metodologia de rápida análise, passível de realização no campo.

O oxigênio dissolvido é de fundamental importância na manutenção da vida aquática e da qualidade da água. Tchobanoglous e Schroeder (1985) afirmam que, devido à sua importância, o oxigênio dissolvido é amplamente utilizado como principal parâmetro de qualidade da água e serve para determinar o impacto de poluentes sobre corpos hídricos.

Para Araújo et. al. (2004) o oxigênio é utilizado como principal parâmetro de qualidade da água e serve para determinar o impacto de poluentes sobre os corpos da água. É um importante fator no desenvolvimento de qualquer planejamento na gestão de recursos hídricos. O consumo de oxigênio é dado pela oxidação da matéria orgânica, respiração dos organismos aquáticos e demanda bentônica de oxigênio (sedimentos). Esse oxigênio é produzido pela reareação da atmosfera (difusão), na fotossíntese e pela entrada no mesmo em tributários e efluentes.

A condutividade expressa a capacidade de condução de corrente elétrica de sais dissolvidos e ionizados presentes numa água, pode ser utilizada como parâmetro de avaliação de qualidade. O método utilizado é o eletrométrico, segundo Matheus et al. (1995).

A turbidez é a alteração da penetração da luz provocada por partículas em suspensão, como bactérias, argilas e silte ou fontes de poluição que lançam materiais finos e outras substâncias na água. A presença dessas substâncias provoca a dispersão e a absorção da luz, dando à água aparência nebulosa, esteticamente indesejável e potencialmente perigosa (PINTO, 1998). Com concentrações recomendadas pelo CONAMA Resolução 357/05, classe I, até 40 unidades nefelométrica de turbidez NTU, Tabela 01 e Quadro 02.

$\mathrm{O} \mathbf{p H}$ apresenta a acidez ou a basicidade das águas, que podem ter origens em fatores naturais do terreno ou resultantes de poluentes dissolvidos na água. A analise do pH será feita através do método eletrométrico (CETESB, 1987). Para analise será utilizado os limites da Resolução CONAMA 357, de 17/03/05, que se estende de 6,0 a 9,0, Tabela 01 e Quadro 02.

A temperatura do ar e da água influencia nos processos biológicos, reações químicas e bioquímicas que ocorrem na água e também outros processos como solubilidade dos gases dissolvidos, além de acentuar a sensação de sabor e odor (PINTO, 1998). Para a análise da temperatura do ar e da água será utilizado o método eletrométrico (CETESB, 1987).

Tabela 01: Limites dos Parâmetros Analisados para Enquadramento nas Classes das Águas Doces no Brasil

\begin{tabular}{|l|l|}
\hline Classes & Limites para o Enquadramento \\
\hline \multirow{3}{*}{ Especial } & $\begin{array}{l}\text { Nas águas de classe especial deverão ser mantidas as condições } \\
\text { naturais do corpo de água. } \\
\text { OD }+10,0 \mathrm{mg} / 1 \\
\text { pH } 6,0 \text { a } 9,0 \\
\text { Turbidez até } 40 \text { NTU }\end{array}$ \\
\hline I & $\begin{array}{l}\text { OD } 10 \text { a } 6 \mathrm{mg} / 1 \\
\text { pH } 6,0 \text { a } 9,0 \\
\text { Turbidez até } 40 \text { NTU }\end{array}$ \\
\hline II & $\begin{array}{l}\text { OD } 6 \text { a } 5 \text { mg/l } \\
\text { pH } 6,0 \text { a } 9,0 \\
\text { Turbidez } 40 \text { até } 100 \text { NTU }\end{array}$ \\
\hline III & $\begin{array}{l}\text { OD } 5 \text { a } 4 \mathrm{mg} / 1 \\
\text { pH } 6,0 \text { a } 9,0 \\
\text { Turbidez } \text { até } 100 \text { NTU }\end{array}$ \\
\hline
\end{tabular}


Anais II Seminário de Recursos Hídricos da Bacia Hidrográfica do Paraíba do Sul: Recuperação de Áreas Degradadas, Serviços Ambientais e Sustentabilidade, Taubaté, Brasil, 09-11 dezembro 2009, IPABHi, p. 189-198.

(doi:10.4136/serhidro.25)

\begin{tabular}{|l|l|}
\hline IV & $\begin{array}{l}\text { OD }-4 \mathrm{mg} / \mathrm{l} \\
\text { pH } 6,0 \text { a } 9,0 \\
\text { Turbidez acima de 100 NTU }\end{array}$ \\
\hline
\end{tabular}

Fonte: Resolução n. 357 do CONAMA de 17/03/2005

Quadro 02: Classificação das águas doces brasileiras, segundo seus usos preponderantes, de acordo com a Resolução CONAMA n. 357/2005.

\begin{tabular}{|l|l|}
\hline Classes & Principais Usos \\
\hline Especial & $\begin{array}{l}\text { Consumo humano com desinfecção; Preservação de equilíbrio natural das } \\
\text { comunidades aquáticas; Preservação dos ambientes aquáticos em unidades de } \\
\text { conservação de proteção integral. }\end{array}$ \\
\hline I & $\begin{array}{l}\text { Consumo humano, após tratamento simplificado; Proteção das comunidades aquáticas; } \\
\text { Recreação de contato primário (natação, esqui aquático e mergulho) Resolução } \\
\text { CONAMA n. 274, de 2000; Irrigação de hortaliças que são consumidas cruas e de } \\
\text { frutas que se desenvolvam rentes ao solo e que sejam ingeridas sem remoção de } \\
\text { películas e à proteção das comunidades aquáticas em Terras Indígenas. }\end{array}$ \\
\hline II & $\begin{array}{l}\text { Abastecimento para consumo humano, após tratamento convencional, à proteção das } \\
\text { comunidades aquáticas, à recreação de contato primário, tais como natação, esqui } \\
\text { aquático e mergulho, Resolução CONAMA n. 274, de 2000, à irrigação de hortaliças, } \\
\text { plantas frutíferas e de parques, jardins, campos de esporte e lazer, com os quais o } \\
\text { público possa vir a ter contato direto e à aqüicultura e à atividade de pesca. }\end{array}$ \\
\hline III & $\begin{array}{l}\text { Abastecimento para consumo humano, após tratamento convencional ou avançado, à } \\
\text { irrigação de culturas arbóreas, cerealíferas e forrageiras, à pesca amadora, à recreação } \\
\text { de contato secundário e à dessedentação de animais. }\end{array}$ \\
\hline IV & Navegação e à harmonia paisagística \\
\hline
\end{tabular}

Fonte: Resolução n. 357 do CONAMA de 17/03/2005

Para a execução da mensuração da competencia de transporte fluvial foram utilizados os seguintes softwares e equipamentos Word 2000; Excel 2007; Corel Draw 12 - Corel Photo-Paint 12 e Software Universal Desktop Ruler - UDR (mensurações areais). Em campo utilizou-se frascos plasticos de $500 \mathrm{ml}$, câmeras digitais fotográficas (registrar as condições atuais) e o Sistema de Posicionamento Global - GPS; pHmêtro, Oxímetro, Condutivímetro e em laboratório, Turbidímetro, Estufa de Secagem, Conjunto de infiltração, Bomba à Vácuo, Balança de Precisão e Membrana Filtrante - Milipores, 47 mícrons, em estér de celulose. Para a análise físico-química dos parâmetros acima apontados embasou-se nas metodologias descritas por CHRISTOFOLETTI (1980); PINTO (1985); PINTO et. al. (2008) e CARVALHO et. al. (2000).

A carga de sedimento dos cursos de água é obtida pela ação erosiva que as águas exercem sobre todo o entorno da bacia e no fundo dos leitos, sendo que, no caso do Córrego Bom Jardim, há ocorrência de cobertura vegetal (mata ciliar) em pouquíssima quantidade, e associado com o tipo de solo friável que constitui toda a bacia. Devido a isso, deve-se reconhecer que os fatores hidrológicos que controlam as características e o regime dos cursos de água.

A carga do leito do rio é composta por partículas de granulometria maior, como as areias e cascalhos, que são transportadas através da saltitação, deslizamento ou rolamento na superfície do leito.

Segundo Christofoletti (1980), os fatores hidrológicos, cujos mais importantes são a quantidade da cobertura vegetal influenciam a formação do material intemperizado na bacia hidrográfica e o carregamento desses materiais até os rios. O fluxo e o transporte de sedimentos constituem respostas aos processos e ao estado de equilíbrio atuante no sistema fluvial.

Para a coleta nos oito pontos selecionados ao longo do canal principal do Bom Jardim e na foz de seus principais afluentes, Figura 01, utilizou-se frascos plasticos de 500ml. Os quais foram 
introduzidos nas áreas de maior velocidade do canal, até o fundo, sem que este afunda-se no leito arenoso, para receber o fluxo de fundo e os sedimentos em rolamento, saltitação e em suspensão, ao longo das estações do ano de inverno de 2008 e verão de 2009.

Em laboratório os frascos foram agitados e colocados, $100 \mathrm{ml}$, em conjunto de infiltração da milipore, com filtro de 4,7 microns de celulose, que em seguida foram a estufa de secagem por 24 horas a $60^{\circ \mathrm{C}}$. Logo após resfriarem os filtros foram pesados em balança de precissão e compará-los com o peso de seus respectivos filtros sem sedimentos, como os valores correspondem a $100 \mathrm{ml}$, estes foram convertidos para $\mathrm{m}^{3}$ e calculados os valores conforme as vazões mensuradas nas estações, no inverno de 2008 e verão de 2009.

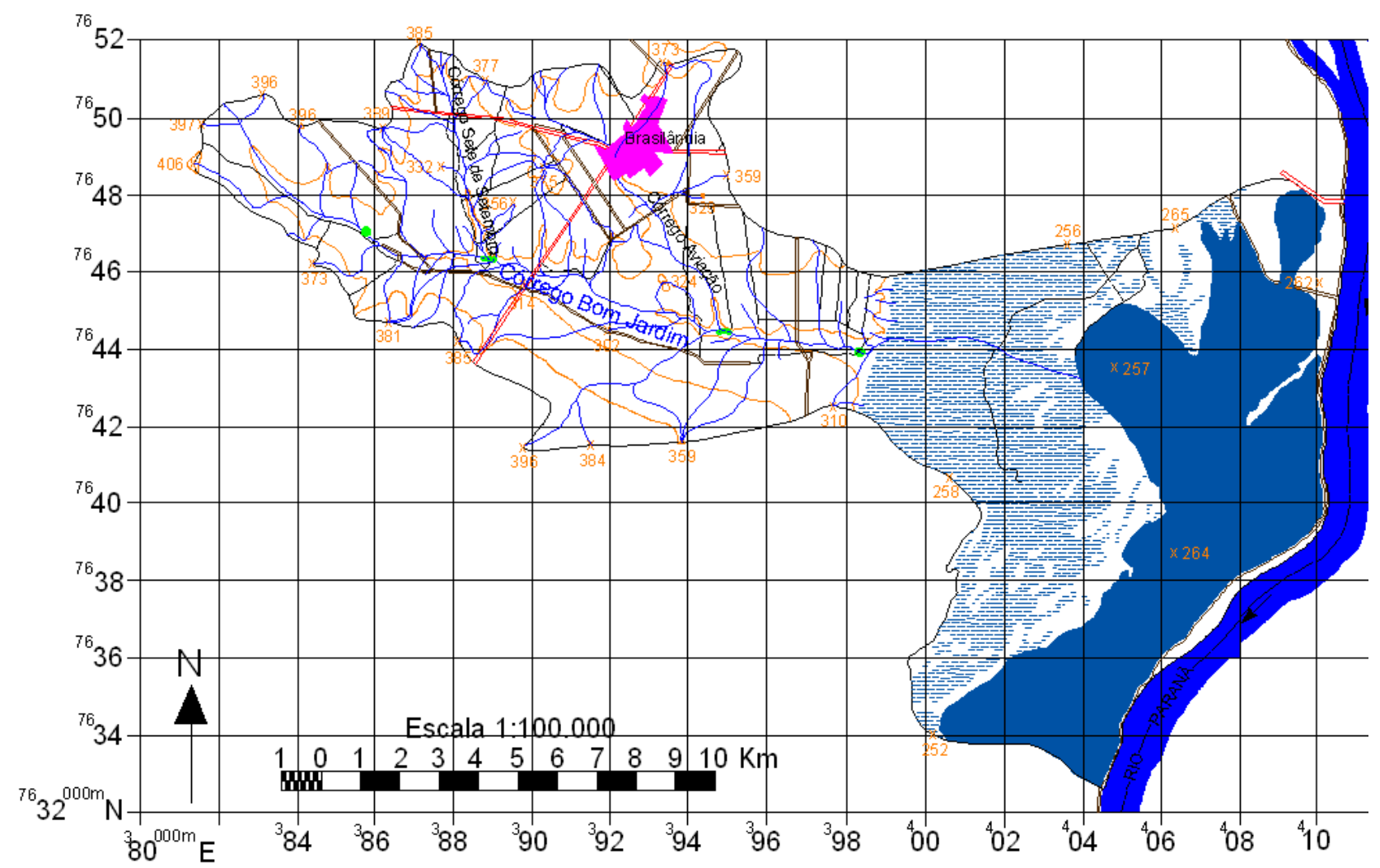

Figura 1: Mapa de localização dos pontos de coleta 


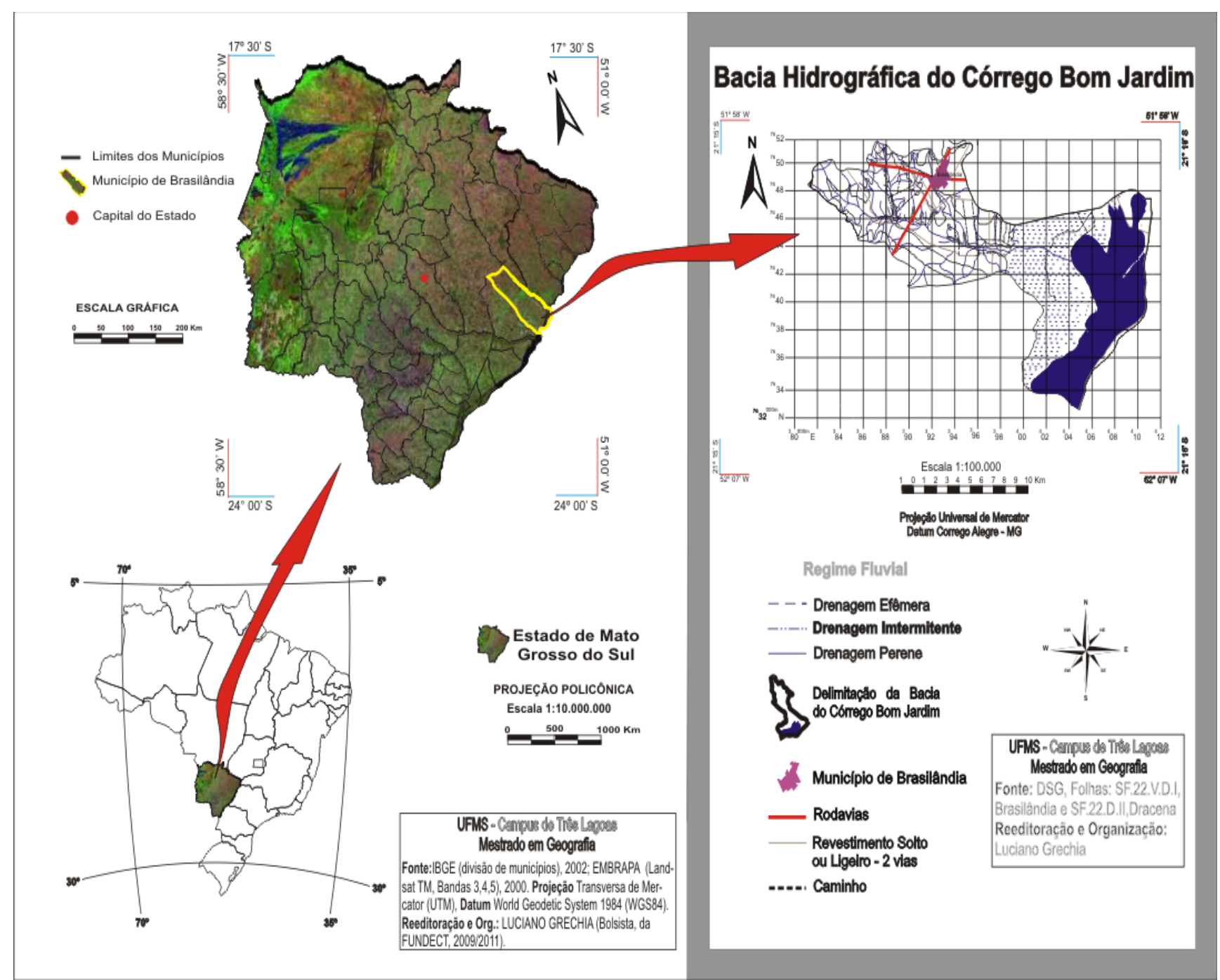

Figura 2: Mapa de localização

\section{Discussão e Resultados}

Na estação 1, o córrego Bom Jardim corre em meio a mata ciliar fechada, que se entrelaça a área de cerrado preservada, da reserva de legal da Fazenda Capela 3- Araraquara, com declividade de 3 a 6\%, em canal encaixado, que impõe uma das maiores velocidade de fluxo da bacia, de 5,72 $\mathrm{m} / \mathrm{s}$, no inverno, em pequena área $0,203 \mathrm{~m}^{2}$, que lhe proporciona elevada competência de transporte de sedimentos, 98,366 toneladas na estação do inverno, a segunda maior nesta estação, só perdendo para foz, ponto 08 .

Tabela 02: Competência de transporte fluvial em Suspensão na bacia do Córrego Bom Jardim/ Inverno 2008

\begin{tabular}{|c|c|c|c|c|}
\hline Estações & Velocidade $(\mathbf{m} / \mathbf{s})$ & Área $\left(\mathbf{m}^{\mathbf{2}}\right)$ & Vazão $\left(\mathbf{m}^{\mathbf{3}} / \mathbf{s}\right)$ & $\begin{array}{c}\text { Transporte de } \\
\text { Sedimentos } \\
\text { tonel/m } \mathbf{3} / \mathbf{i n v e r n o}\end{array}$ \\
\hline 1 & 5,72 & 0,203 & 1,15 & 98,366 \\
\hline 2 & 2,42 & 0,503 & 1,21 & 75,271 \\
\hline
\end{tabular}


Anais II Seminário de Recursos Hídricos da Bacia Hidrográfica do Paraíba do Sul: Recuperação de Áreas Degradadas, Serviços Ambientais e Sustentabilidade, Taubaté, Brasil, 09-11 dezembro 2009, IPABHi, p. 189-198.

(doi:10.4136/serhidro.25)

\begin{tabular}{|c|c|c|c|c|}
\hline 3 & 3,77 & 0,801 & 3,01 & 0,0 \\
\hline 4 & 3,04 & 0,995 & 3,44 & 26,749 \\
\hline 5 & 1,62 & 1,133 & 1,82 & 14,152 \\
\hline 6 & 1,19 & 0,28 & 0,33 & 10,264 \\
\hline 7 & 1,59 & 1,163 & 1,84 & 57,231 \\
\hline 8 & 2,73 & 2,223 & 6,06 & 471,225 \\
\hline
\end{tabular}

Tabela 03: Competência de transporte fluvial em Suspensão na bacia do Córrego Bom Jardim/ Verão 2009

\begin{tabular}{|c|c|c|c|c|c|}
\hline \multirow{2}{*}{ Estações } & \multirow{2}{*}{$\begin{array}{c}\text { Velocidade } \\
(\mathrm{m} / \mathrm{s})\end{array}$} & \multirow{2}{*}{$\begin{array}{c}\text { Área } \\
\left(\mathbf{m}^{2}\right)\end{array}$} & \multirow{2}{*}{$\begin{array}{l}\text { Vazão } \\
\left(\mathrm{m}^{3} / \mathbf{s}\right)\end{array}$} & \multicolumn{2}{|c|}{ Transporte de Sedimentos } \\
\hline & & & & $\mathrm{g} / \mathrm{m}^{3} / \mathrm{s}$ & ton $/ \mathrm{m}^{3} /$ verão \\
\hline 1 & 6,58 & 0,73 & 4,80 & 48,1 & 498,70 \\
\hline 2 & 1,68 & 6,22 & 10,45 & 114,95 & $1.191,80$ \\
\hline 3 & 2,24 & 2,69 & 6,03 & 24,12 & 250,07 \\
\hline 4 & 1,64 & 16,48 & 27,03 & 919,02 & $9.528,40$ \\
\hline 5 & 1,85 & 10,64 & 19,68 & 137,76 & $1.428,29$ \\
\hline 6 & 1,51 & 4,41 & 6,66 & $1.538,46$ & $15.950,75$ \\
\hline 7 & 2,45 & 20,11 & 49,27 & 147,81 & $1.532,49$ \\
\hline 8 & 2,90 & 18,08 & 52,43 & 314,58 & $3.261,56$ \\
\hline
\end{tabular}

No verão de 2009 a competência de transporte de sedimentos é maior como se apresenta na tabela acima, No ponto 6 Córrego Aviação, corta a cidade de Brasilândia e recebe seu esgoto domiciliar no verão o ponto 06 no valor de 15.950,75 toneladas, mostra um valor mais elevado em relação a competência de transporte da estação seca.

Faz- se necessario lembrar que esse aumento no transporte de sedimento tem total relação com o revestimento vegetal, nos pontos 5 e 7, os canais são largos em vale amplo sem cobertura vegetal primitiva, que influenciam na baixa concentração de OD, consequentemente interferindo na sua qualidade.

\section{Considerações Finais}

Constata-se que a qualidade da água no corpo d’água avaliado é fortemente influenciada pelo uso e a ocupação da terra das áreas imediatas ao eixo bacia. Influências diretas vinculam-se também as fluviometria e morfometria de cada segmento, com evidentes reflexos na qualidade física, química e biológica da água.

Além de manejo inadequado do gado criado extensivamente, com acesso ao canal fluvial, que constitui sua única opção para sedentação animal. A partir do presente estudo sugere-se para o segmento de alto curso o tratamento dos esgotos urbanos e a revegetação integral das imediações do eixo da bacia, desde o sistema lacustre de montante até o curso final do Córrego Bom jardim e o acompanhamento sistemático da qualidade da água de todos os corpos que integram a Bacia Hidrográfica do Bom Jardim.

Apesar da manifesta preocupação da Prefeitura Municipal de Brasilândia em relação à qualidade ambiental, constata-se que poucas ações de cumprimento da legislação estão sendo implementadas. O fato é atribuído à completa desestruturação do poder público local no tocante à fiscalização e a punição daqueles que cometem crimes ambientais. 


\section{Bibliografia}

American Public Health Association. Standard methods for the examination of water and wastewater. 17 th ed. APHA/AWWA/WPCF, Washington, 1989.

APHA Microbiological examination of water. IN: Standerd methods for examination of water and wastewater. 18 th ed. Washington, APHA/AWWA/WPCF, 1995.

ARAÙJO, S. C. de S.; SALLES, P. S. B. de A.; SAITO, C. H. Modelos qualitativos, baseados na dinâmica do oxigênio dissolvido, para avaliação da qualidade das águas em bacias hidrográficas. Desenvolvimento tecnológico e metodológico para medição entre usuários e comitês de bacia hidrográfica. Brasília: Departamento de Ecologia. Editora da UNB, 2004. p.9-24.

BRASIL, LEI No 9.433, DE 8 DE JANEIRO DE 1997

Institui a Política Nacional de Recursos Hídricos, cria o Sistema Nacional de Gerenciamento de Recursos Hídricos, regulamenta o inciso XIX do art. 21 da Constituição Federal, e altera o art. $1^{\circ}$ da Lei ${ }^{\circ}$ 8.001, de 13 de março de 1990, que modificou a Lei $n^{\circ}$ 7.990, de 28 de dezembro de 1989.

BRASIL. Resolução 357 de 17 de março de 2005. Brasilia (DF): Conselho Nacional do Meio Ambiente - CONAMA, 2005.

CARVALHO, A.R.; SCHLITLER, F.H.M.; TORNISIELO, V.L. Relações da atividade agropecuária com parâmetros físicos químicos da água. Química Nova. São Paulo. v.23, n.5, p.618-624, 2000.

CASSETI, V. Elementos de Geomorfologia. Goiânia: Editora de UFG, 1994.

CESP Plano de Manejo da Reserva Cisalpina. Companhia Energética de São Paulo: Relatório. São Paulo, 2007: 234p.

CETESB. Companhia de Tecnologia de Saneamento Básico. Guia de coleta e preservação de amostras de água. São Paulo, 1987: 150p. (Séries guias)

ESPÍNDOLA, E.L.G. et. al. - A Bacia Hidrográfica do Córrego Monjolinho. RIMA. USP -Escola de Engenharia de São Carlos. São Carlos, 2000.

CHRISTOFOLLETTI, Antônio. Geomorfologia. São Paulo, Edgard Blücher, 2ª edição, 1980.

DARBELLO, D. de M. Monitoramento das águas superficiais da bacia do Córrego Fundo, Aquidauana/MS. 2006. 55 f. Relatório Final de Iniciação Científica. UFMS, Campus de Aquidauana, Aquidauan/MS.

Pinto, A. L. ; A importancia do Ribeirão Claro para o Abastecimento de água da cidade de Rio Claro-SP. In:Geografia Teorética-vol.15 1985.

PINTO, A. L. Saneamento Básico e suas Implicações na Qualidade das Águas Subterrâneas da Cidade de Anastácio (MS). 1998. 175p. Tese (Doutorado e 
Geociências) - Universidade Estadual Paulista/Instituto de Geociências e Ciências Exatas, Rio Claro, 1998.

ROCHA, O; PIRES, J. S. R.; SANTOS, J.E. dos. A bacia hidrográfica como unidade de estudo e planejamento. In: A bacia Hidrográfica do Rio Monjolinho: Uma abordagem Ecossistêmica e a visão interdisciplinar. São Paulo: Rima, 2000. p.1-16.

Standerd methods for examination of water and wastewater. 15 th ed. Washington, APHA/AWWA/WPCF, 1980. 